\title{
TEORIAS DE LOCALIZAÇÃO APLICADAS ÀS EMPRESAS DE BASE TECNOLÓGICA: UM ESTUDO EMPIRICO
}

\author{
João José de Matos Ferreira \\ Professor da Universidade da Beira Interior, Portugal \\ Doutor em Gestão pela Universidade da Beira Interior, Portugal \\ jjmf@ubi.pt
}

\section{Carla Susana Marques}

Professor da Universidade Trás-os-Montes e Alto Douro, Portugal

Doutora em gestão pellaUniversidade Trás-os-Montes e Alto Douro, Portugal smarques@utad.pt

\section{Cristina Fernandes}

Mestre emGestão, pela Universidade da Beira Interior, Portugal tmf3@sapo.pt

\section{RESUMO}

A área do desenvolvimento regional tem merecido especial atenção por parte de diversos investigadores. Empreendedorismo, clusters, inovação, universidades e empresas de base tecnológica são áreas de conhecimento que têm mostrado um papel principal na contribuição do desenvolvimento regional e, especificamente, no estudo das teorias de localização. Esta investigação visa identificar quais os factores que influenciam a localização das empresas de base tecnológica. Para alcançar tal objetivo um estudo empírico foi conduzido com base em 203 questionários a empresas de base tecnológica localizadas na região da Beira Interior (Portugal). Os resultados evidenciaram a possibilidade de identificar factores cruciais que influenciam a localização dessas empresas. Esses fatores são de natureza comportamental, institucional e neoclássica.

Palavras-chave: Desenvolvimento regional; Empresas de base tecnológica; Teorias de localização. 


\section{INTRODUÇÃO}

A atividade empreendedora, assim como todos os fatores que estão por de trás da sua existência e a sua influência no desenvolvimento económico regional têm sido objeto de estudo por parte de diversos autores (Birley, 1985; Kirchoff \& Phillips, 1988; Storey, 1994). A questão do desenvolvimento regional tem despertado interesse nos mais diversos investigadores, nacionais (o interesse deve-se essencialmente à existência de assimetrias regionais) e internacionais (o interesse deve-se a todos os acontecimentos que envolvem a Europa e, mais concretamente, a União Europeia) (Lopes, 1998; Cooke, 2002; Santos, 2002 e 2005; Rego, 2003).

O empreendedorismo aparece também como um acontecimento que contribui para o desenvolvimento regional (Raposo et al., 2004). O White Paper (2001), da National Commission on Entrepreneurship (NCOE), defende que o maior contributo do empreendedorismo a nível local é a inovação. Associada à questão da importância do empreendedorismo para o desenvolvimento regional, aparece inevitavelmente, a questão das teorias da localização, ou seja, o que leva os empresários (que provocam a atividade empreendedora) a escolherem determinado local para implementarem a sua empresa (Hayter, 1997; Silva, 2005; Roper \& Love, 2006).

As áreas rurais ainda estão muito aquém das suas homólogas urbanas, principalmente no que respeita à criação de empresas de base tecnológica. Face a esta problemática, levantamos a seguinte questão de investigação: Quais as razões que levam as empresas de base tecnológica a estabelecerem-se em determinada região? Em particular, quais os fatores de localização das empresas de base tecnológica da Beira Interior? Temos como principal objetivo tentar dar reposta a esta questão. Após esta breve introdução, iremos sistematizar as principais abordagens teóricas sobre a localização das empresas, onde propomos o nosso modelo conceptual de investigação e formulamos as nossas hipóteses de investigação, de acordo com o mesmo. Em seguida, apresentaremos os aspectos metodológicos, onde apresentaremos os critérios de classificação das indústrias de base tecnológica, definimos a nossa amostra e descrevemos os procedimentos estatísticos usados e testamos o nosso modelo de investigação. Seguidamente analisamos e discutimos os resultados obtidos. Por último são feitas as considerações finais da investigação.

Revista de Administração e Inovação, São Paulo, v. 7, n. 4, p.43-65, out./dez. 2010 


\section{ABORDAGENS TEÓRICAS SOBRE A LOCALIZAÇÃO DAS EMPRESAS}

De acordo com Silva (2005), a distribuição espacial das atividades económicas é o resultado de oportunidades e de estratégias de localização traçadas em função de determinados objetivos. No entanto, os processos de decisão são complexos e envolvem uma importante componente económica, pois grande parte das atividades humanas envolve a utilização e a partilha de recursos limitados.

De acordo com Arauzo e Viladecans (2006), a localização das atividades económicas, tem merecido uma atenção especial por parte dos investigadores, há muitos anos. Von Thünen (1826) debruçou o seu estudo no conceito de renda fundiária, no qual defende que o fator distância é o mais importante na definição da localização da renda fundiária, tal qual ela ocorria. Marshall (1890) deu especial atenção às economias de aglomeração e ao conceito de distrito industrial, Weber (1909) começou por abordar a localização da indústria, dando particular importância à minimização dos custos. Para Weber (1909) existiam três fatores que determinariam a localização de uma empresa industrial: o custo de transporte; os custos de trabalho; e as vantagens associadas à aglomeração (economias de aglomeração). Hoover (1948) estudou, o que ele defendia, como a divisão espacial do mercado, combinando aglomeração e custos de transporte. Lösch (1954) fez a sua investigação sobre a área de mercado, na qual admite que o mercado é homogéneo, tal como a procura e que os custos de transporte são proporcionais à distância a percorrer e, Christaller (1933), explorou a sua teoria dos lugares centrais.

Segundo Capello (2007), existem dois grupos de teorias, (as quais chama regional economics), que abordam a questão da lógica económica que pretende explicar a localização de empresas ou, de outra forma, porque é que existem áreas mais desenvolvidas do que outras: (i) Teorias de localização: mecanismos económicos que provocam a distribuição das atividades no espaço; (ii) Teorias do Crescimento e desenvolvimento regional: centram-se nos aspectos espaciais do crescimento económico e da distribuição territorial do rendimento.

Por outro lado, Hayter (1997) propõe analisar a localização da atividade económica através de três abordagens distintas: (i) neoclássica, que se dedica maioritariamente à teoria de localização e centra a sua análise em estratégias de maximização do lucro e de minimização dos custos (ex.: custos de transporte, custos de mão de obra e economias externas; (ii) institucional, afirma que é importante não só considerar a empresa que procura um local adequado como também o meio institucional onde ela se encontra (clientes, fornecedores, associações comerciais, sistemas regionais, o governo e as outras empresas); e (iii) comportamental, que aborda situações de incerteza e falta de informação. 
Dentre toda a literatura revista que se debruça sobre os fatores de localização das empresas de base tecnológica, optamos por seguir a classificação conceitual proposta por Hayter (1997). De acordo com este autor, estas três abordagens servem para nos demonstrar o quão complexas são as razões que motivam a localização de uma atividade económica e permitem analisar os fatores de localização a um nível mais micro. No ponto seguinte faemos uma breve caracterização destas abordagens, dando a perspectiva e a contribição de diversos autores.

\section{ABORDAGEM NEOCLÁSSICA}

Existem diversas investigações, como a seguir se mostra, que se centram nos fatores de localização das empresas de base tecnológica, no entanto, poucas dessas análises refletem os motivos pelos quais essas empresas decidiram estabelecer-se em zonas rurais. A explicação a essa escassez de informação provavelmente é o pequeno número de empresas localizadas em áreas rurais. Contudo, devido ao desenvolvimento das tecnologias de informação, e especialmente da internet, Grimes (2000) identificou um incremento do número de empresas que se implantaram nestas áreas.

De acordo com Ouwersloot e Rietveld (2000), um dos pontos-chave do desenvolvimento económico é a inovação tecnológica, ou seja, a introdução de novas técnicas de produção, produtos ou serviços. No entanto o aparecimento destes novos elementos é usualmente precedido por um processo intensivo de Investigação e Desenvolviemento (I\&D). Assim, e segundo estes investigadores, a localização de atividades de I\&D é influenciada por diversos fatores. Identificaram, então, quatro fatoresexternos às empresas que podem influenciar as decisões de localização: (i) oferta de trabalho; (ii) infraestruturas do conhecimento; (iii) infraestruturas físicas; e (iv) efeitos de aglomeração. Estes investigadores, concluíram que dependendo do tipo de empresa é o fator decisivo que as leva a localizarem-se em determinada região. Ou seja, para as empresas tradicionais de transformação, a composição industrial do local onde se vão implementar é fator principal. Fatores como as infraestruturas físicas e instituições nas quais se gera conhecimento são fundamentais para a decisão de localização das empresas de serviços.

Holl (2004) centrou na Espanha sua investigação dos impactos que as novas infraestruturas rodoviárias tiveram no aparecimento de empresas transformadoras. Ao contrário de muitas investigações anteriores, esta fez a sua análise ao nível micro, para explorar as variações na localização, a uma escala geográfica detalhada. Por intermédio dos resultados empíricos, o autor 
conclui que, num país como a Espanha, onde a rede de autoestradas foi desenvolvida recentemente (1980-1994) e onde as diferenças intra e inter-regionais estão muito presentes, o acesso às infraestruturas rodoviárias faz toda a diferença, na hora decidir onde localizar uma nova empresa.

Costa et al. (2004) analisaram os mecanismos que levaram à localização de novas empresas de base tecnológica na Espanha, e propuseram que a localização das empresas tinha a ver com o tipo de indústria e com o ciclo de vida do produto, sobre o qual a empresa estava relacionada a sua atividade. Assim, quando o empresário encontra um local para implementar a sua empresa, deve analisar se esse meio envolvente é o mais favorável para efetuar o seu processo produtivo. Esse meio pode ser mais ou menos populoso e conter maior ou menor variedade de atividades produtivas. No entanto, pelo seu estudo empírico, concluíram que as cidades mais populosas e desenvolvidas perderam atratividade relativamente à localização de empresas, face às suas homólogas, mais pequenas e mais rurais. Não obstante, quando observaram, as novas empresas de base científica preferem localizar-se e aglomerarse nas grandes cidades espanholas. Assim, a localização das empresas é mais próxima ou mais afastada dos grandes centros dependendo do tipo de atividade da empresa.

De acordo com a abordagem neoclássica e segundo Hayter (1997), a localização das empresas assenta essencialmente no poder das forças económicas. A verdade é que, na prática, dependendo do perfil do empreendedor, este pode perfeitamente ignorar o poder dessas forças. De acordo com este autor, esta situação provoca muitas vezes uma influência perversa nas teorias dos investigadores que apenas defendem a abordagem neoclássica, pois pelo "senso comum", assim como pelas vantagens económicas, o empreendedor, quando escolhe o local onde vai implementar a sua empresa, tem em conta todo o tipo de custos, localizando, desse modo, onde estes sejam mais baixos. É precisamente devido a esta problemática, e porque para Hayter, este fator não explica por si só a localização das empresas, o autor desenvolveu também as duas abordagens que se seguem: institucional e comportamental.

Em suma, na abordagem neoclássica, os fatores que proporcionam o aparecimento das empresas são as infraestruturas rodoviárias, os locais serem mais ou menos populosos e o tipo de indústria que se pretende implementar. 


\section{ABORDAGEM COMPORTAMENTAL}

Galbraith (1985) estudou 98 administradores de empresas de alta tecnologia com uma média de 670 trabalhadores, em Orange County, Califórnia (EUA). O autor concluiu que as empresas de alta tecnologia, durante o seu processo de tomada de decisão de localização, operam num conjunto diferente de fatores que não os da indústria tradicional. Esse autor identificou três aspectos que determinam a localização deste tipo de empresas: avaliação da personalidade pessoal e profissional; cultura e modo de vida; e o desejo do fundador da empresa de viver nessa localidade. Estas conclusões são também suportadas por Arauzo e Viladecans (2006), no seu estudo sobre o nível de concentração espacial das novas empresas (no período 1992-1996) nos municípios das áreas urbanas espanholas. Os autores entendem que o processo de sub-urbanismo é especialmente importante para as empresas de alta tecnologia. Estas empresas deslocam-se das grandes cidades nas grandes áreas urbanas (a sua localização tradicional), para as cidades mais pequenas que, desta forma, acabam por melhorar as suas acessibilidades, devido aos investimentos em infraestruturas rodoviárias. Aliás, as cidades mais pequenas parecem ser as preferidas para a localização das empresas de base tecnológica; pois oferecem um meio evolvente mais calmo, com mais qualidade de vida, extremamente valorizada pelos indivíduos qualificados que trabalham nessas indústrias.

Felsenstein (1996) defende que as áreas urbanas têm uma rede física de infraestruturas melhor que as áreas não urbanas (ex.: telecomunicações), sendo esta razão suficiente para que os empresários as prefiram para localizarem as suas empresas. No entanto, baseando-se num estudo, que fez a uma amostra de 160 empresas, tanto de áreas urbanas como não urbanas, em Telavive (Israel), analisou qual a tendência das empresas de alta tecnologia, de escolherem áreas urbanas para se fixarem. $\mathrm{O}$ autor concluiu que, a localização das empresas não segue uma estratégia, nem um cálculo; ou seja, não é uma decisão fundamentada. Parece ser especialmente o caso das pequenas novas empresas que nascem em uma localidade, sem uma estratégia de fundo definida. No entanto, acabou por observar e concluir que uma das características da rede de novas empresas é precisamente não se localizarem em áreas urbanas.

De acordo com Hayter (1997), a localização de muitas empresas é explicada por esta abordagem, pois muitos empreendedores, no momento em que decidem onde localizar a sua empresa, acabam por fazê-lo nos locais de onde são naturais, deixando os fatores neoclássicos de lado. De acordo com o mesmo autor, esta perspectiva vai contra os princípios económicos, uma vez que apenas

Revista de Administração e Inovação, São Paulo, v. 7, n. 4, p.43-65, out./dez. 2010 
se avaliam fatores comportamentais. No entanto, esta abordagem explica grande parte do aparecimento das pequenas e médias empresas.

Em suma, na abordagem comportamental, os investigadores defenderam que a localização das empresas prende-se essencialmente com a qualidade de vida e as características de cariz pessoal dos empresários.

\section{ABORDAGEM INSTITUCIONAL}

Uma outra abordagem ao estudo da localização das empresas de base tecnológica, a abordagem institucional, é adotada por Elgen et al. (2004). A sua investigação teve como objetivo verificar qual o papel que os institutos públicos de investigação têm na captação/ atração para perto de si, de novas empresas de base tecnológica. Para tal usaram 20.000 novas empresas alemãs criadas especificamente com base no conhecimento intensivo das instituições de investigação. Os resultados a que chegaram mostram que estas start-ups de alta tecnologia tendem a confiar de uma forma muito "intensa" na ciência, levando-as a localizarem-se perto de instituições de investigação. No entanto, as novas empresas de serviços tendem a afastar-se destas mesmas instituições. Assim, pode dizer-se que dependendo do nível de tecnologia necessário à actividade de uma empresa, assim esta se localiza mais perto ou mais afastada das instituições de investigação.

Meyer (2003) acrescenta algo mais à investigação dos autores anteriores, pois para este autor, outro fator muito importante e que influencia a localização de empresas é o fato de existir, numa determinada localidade, uma incubadora de empresas. Sendo esta instituição muito importante na hora em que se faz a opção de se localizar uma empresa num determinado local. Num estudo similar, tendo as novas empresas de base tecnológica como unidade de análise, Audrestch et al. (2005) focaram a importância do acesso a spillovers de conhecimento, no momento em que as novas empresas de base tecnológica decidem localizar-se. Neste modelo, os autores incluem: a distância das empresas às universidades em quilómetros, o número de artigos científicos publicados pelas universidades, o número de estudantes em ciências exatas e em ciências sociais, número de habitantes, o preço da diária no hotel mais caro e a idade média das empresas. Os seus resultados mostraram que as novas empresas de alta-tecnologia são influenciadas por outros fatores que não as características tradicionais regionais, mas sim a oportunidade de acesso ao conhecimento gerado pelas universidades.

Revista de Administração e Inovação, São Paulo, v. 7, n. 4, p.43-65, out./dez. 2010 
Autant-Bernard et al. (2006) analisaram os determinantes da criação das novas empresas de biotecnologia na França, durante a última década (1993-1999), para compreenderem o papel do meio envolvente local, na comercialização dos resultados científicos. Basearam-se, então, em três determinantes fundamentais: proximidade dos recursos de conhecimento, meio envolvente local, e meio envolvente da indústria. Os resultados a que chegaram estes autores mostram que é necessário que exista, dentro de uma região, uma grande e diversificada base científica para que essas empresas, depois de serem criadas, continuem a sua atividade por muitos anos. Observando o caso de outro país da Península Ibérica, Espanha, Alonso (1999) e Trullén (2001) defendem que, as empresas de base tecnológica, tendem a aglomerar-se na periferia das grandes áreas urbanas, especialmente quando estas empresas recém-criadas têm mais de 100 colaboradores, para, desta forma, captarem a tecnologia criada por outros agentes e terem custos mais baixos. De acordo com Hayter (1997), existem também os empreendedores que preferem localizar-se perto das universidades, centros de investigação e de órgão governamentais, para terem apoio mais adequado às atividades que pretendem desenvolver no seio das suas organizações.

Em suma, os autores que, referenciamos, entendem que os fatores de localização das empresas se prendem, com a existência de incubadora de empresas, com a proximidade ou o afastamento de institutos públicos de investigação e de cidades mais ou menos populosas.

Face à sistematização apresentada e atendendo às três abordagens dos fatores de localização das empresas de base tecnológica, apresentamos na Figura 1, o nosso modelo de investigação. O modelo pretende evidenciar os principais factores que influenciam as decisões de localização das empresas de base tecnológica. 


\section{Factores Institucionais:}

- Incubadora de empresas.

Iniversidades ou centros de investigação.

- Incentivos de I\&D, criação de empresas, de postos de trabalho.

- Empresários de referência.

- Feiras Tecnológicas.

\section{Factores Neoclássicos:}

- Distancia à capital do município;

- Infra-estruturas rodoviárias;

- Nível de atividade económica da região;

- Custos da propriedade industrial;

- Outras infraestruturas físicas.

- Especialização das empresas da região.

Decisões de

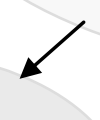

localização das

empresas de base

tecnológica

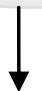

Fatores Comportamentais:

- $\quad$ O fundador decide viver nesse local;

- Desejos dos colaboradores de viverem nessa localidade

- Boas condições de alojamento;

- Oportunidades recreativas e de lazer;

- O fundador nasceu nessa localidade;

- Atitude da comunidade face aos negócios;

- Proximidade da residência do fundador.

Figura 1: Modelo de investigação proposto.

Fonte: Elaborado pelos autores.

Face ao modelo conceptual, foram formuladas as seguintes hipóteses de investigação (Quadro 1) relativamente a cada um dos fatores de localização reflectidos no modelo. 
Quadro 1 - Hipóteses de investigação

\begin{tabular}{l}
\hline Dimensão \\
\hline \\
Fatores comportamentais \\
H1: Os fatores \\
comportamentais \\
influenciam a localização \\
das empresas de alta \\
média e baixa tecnologia, \\
na Beira Interior
\end{tabular}

Fatores Neoclássicos

$\mathrm{H} 2$ : Os fatores

neoclássicos determinam a localização das empresas de alta média e baixa tecnologia, na Beira Interior
Hipóteses de investigação

H1a: O desejo do fundador em viver nesta localidade, influencia a localização das empresas de alta média e baixa tecnologia

H1b: O desejo dos colaboradores em viverem nesta localidade influencia a localização das empresas de alta média e baixa tecnologia

H1c: A proximidade da residência do fundador influencia a localização das empresas de alta média e baixa tecnologia

H1d: O acesso a boas condições de alojamento influencia a localização das empresas de alta média e baixa tecnologia

H1e: O local de nascimento do fundador influencia a localização das empresas de alta média e baixa tecnologia;

H1f: As oportunidades recreativas e de lazer influenciam a localização das empresas de alta média e baixa tecnologia;

H1g: O clima da região influencia a localização destas empresas;

H1h: A Atitude da comunidade em relação aos negócios influencia a localização das empresas de alta média e baixa tecnologia

H2a: A distância à capital do município influencia a localização das empresas de alta média e baixa tecnologia;

H2d: O custo dos terrenos influencia a localização das empresas de alta média e baixa tecnologia

H2b: As infra-estruturas rodoviárias influenciam a localização das empresas de alta média e baixa tecnologia

H2c: Outras infra-estruturas físicas influenciam a localização das empresas de alta média e baixa tecnologia

H2e: O nível da atividade económica do município/região influencia a localização das empresas de alta média e baixa tecnologia

H2f: A especialização das empresas da região influencia a localização das empresas de alta média e baixa tecnologia.

Factores Institucionais

H3: Os fatores institucionais determinam a localização das
H3a: A existência de uma incubadora de empresas na região influencia a localização das empresas de alta média e baixa tecnologia

$\mathrm{H} 3 \mathrm{~b}$ : $\mathrm{O}$ acesso ao conhecimento gerado pelas universidades,
Estudos

Elgen et al. (2004)

Mayer (2003)

Audrestch et

al. (2005)

Autant-

Bernard et al. (2006)

Alonso e

Trullén

(2001)

Hayter

(1997)

Grimes

(2000)

Ouwersloot e

Rietveld

(2000)

Holl (2004)

Costa et al. (2004)

Hayter

(1997)

Galbraith

(1985)

Arauzo e 
empresas de alta média e baixa tecnologia, na Beira Interior

\begin{abstract}
parques tecnológicos ou centros de investigação influencia a
localização das empresas de alta média e baixa tecnologia

H3c: Os incentivos de I\&D, de criação de empresas ou de criação de emprego para localizar os negócios nesta região influenciam a localização das empresas alta média e baixa tecnologia
\end{abstract}

H3d: As feiras tecnológicas realizadas periodicamente na região influenciam a localização das empresas alta média e baixa tecnologia

H3e: Os modelos de "referência" na região influenciam a localização das empresas de alta média e baixa tecnologia.
Viladecans

(2006)

Felsenstein

Hayter

(1997)

\section{Quadro 1 - Hipóteses de investigação.}

Fonte: Elaborado pelos autores.

\section{ASPECTOS METODOLÓGICOS}

A classificação de indústrias de base tecnológica inclui a classificação da OCDE (2003) para empresas transformadoras de base intensiva de atividades de $I \& D$, tendo em conta tudo aquilo com que essas empresas podem contribuir para o país em I\&D e produção de valores e valor acrescentado para o mesmo, resultando, assim, quatro categorias fundamentais: (i) indústrias de alta-tecnologia; (ii) indústrias de média-tecnologia; (iii) indústrias de média-baixa tecnologia; (iv) indústrias de baixatecnologia.

A OCDE, tem usado especificamente a densidade populacional, para medir a ruralidade, ou seja, todas as áreas com menos de 150 habitantes por km², são áreas rurais (OCDE, 1996). Em termos regionais, a OCDE considera rurais todas as áreas de NUT (Nomenclatura de Unidade Territorial) III com mais de $50 \%$ da sua população a viverem em municípios rurais. A Comissão Europeia (1997) também usa a densidade populacional para medir a ruralidade, esta qualifica como rural todas as áreas com densidade populacional abaixo dos 100 habitantes por $\mathrm{km}^{2}$.

Atendendo aos critérios apresentados, a nossa unidade de análise (região da Beira Interior) é "rural" em todas as localidades que a compõem.

Os objetivos da nossa investigação prendem-se com a análise e identificação dos fatores que influenciam as decisões de localização das empresas de base tecnológica na Região da Beira Interior (Portugal). Pretendemos ainda: (i) validar empiricamente modelo conceptual proposto, das decisões de localização das empresas de base tecnológica na Beira Interior; (ii) identificar quais os factores que 
influenciam a localização das empresas de base tecnológica na Beira Interior; e (iii) caracterizar as empresas nos diferentes níveis de tecnologia e detectar possíveis diferenças entre esses níveis. Os principais aspectos metodológicos estão sistematizados no seguinte modo (Quadro 2):

Quadro 2 - Ficha Técnica de Investigação

\begin{tabular}{l|l}
\hline Região & Beira Interior (distritos da Guarda e de Castelo Branco) - Portugal \\
\hline População & $\begin{array}{l}550 \text { Empresas industriais de base tecnológica (60\% alta tecnologia; } \\
14 \% \text { média tecnologia e 26\% de baixa tecnologia) }\end{array}$ \\
\hline Unidade de amostra & Empresas industriais de base tecnológica \\
\hline Tamanho da amostra & 203 respostas (taxa de resposta de 36,9\%) \\
\hline Inquiridos & Empresários - proprietários das empresas \\
\hline Modelo do questionário & $\begin{array}{l}\text { O questionário é constituído por questões fechadas, com utilização de } \\
\text { uma escala de likert. }\end{array}$ \\
\hline Método de recolha da informação & Inquérito administrado pessoalmente (face-to-face) \\
\hline Modelos estatísticos utilizados & $\begin{array}{l}\text { Teste de Qui-quadrado e Kruskal-Wallis, Análise factorial dos } \\
\text { componentes principais; }\end{array}$ \\
\hline Análise de dados & SPSS 15.0 \\
\hline
\end{tabular}

\section{Quadro 2 - Ficha Técnica de Investigação.}

Fonte: Elaborado pelos autores.

\section{ANÁLISE ESTATÍSTICA}

Para identificarmos os fatores de localização das empresas de alta, média e baixa tecnologia, na Beira Interior, procedemos a uma análise fatorial em 19 itens do questionário. O objetivo da aplicação dessa técnica de análise foi obter um número reduzido de fatores que permitam identificar as relações estruturais entre as 19 variáveis que aferem a importância dos fatores de localização das empresas. O método de extração de fatores aplicado foi o método dos componentes principais através do método varimax, com o intuito de obter uma estrutura fatorial na qual uma e apenas uma das variáveis originais esteja fortemente associada com um único fator e pouco associada com os restantes fatores (Maroco, 2003).

A estimação dos "fator scores" foi efetuada pelo método de Bartlett, isto é, método dos mínimos quadrados ponderados. A análise fatorial dos componentes principais para as 19 variáveis em estudo inclui 196 empresas. Todas as variáveis que saturavam mais que um fator seriam eliminadas (o critério de saturação foi o coeficiente 0,40). Não se eliminaram itens, ficando as 19 variáveis em estudo $(\mathrm{KMO}=0,759$ e teste de esfericidade de Bartlett $=1347,702$ com significância: 0,000). 
De acordo com a regra de extração dos fatores com valores próprios superiores a 1 é sugerido que sejam extraídos cinco fatores (motivações pessoais; inovação e incentivo à criação de empresas; características da localidade; expansão económica da região; condições do meio envolvente) que explicam cerca de $62 \%$ da variabilidade total. Iniciou-se o processo de análise fatorial eliminando-se da matriz de componentes as variáveis com pesos fatoriais inferiores a 0,40 , em valor absoluto.

O Quadro 3 mostra o agrupamento dos 19 itens distribuídos pelos 5 fatores, os valores próprios para cada fator e a percentagem de variância explicada e a consistência interna de cada fator a partir do coeficiente de alpha de Cronbach.

\begin{tabular}{|c|c|c|c|c|c|}
\hline & $\begin{array}{c}\text { Fator } 1 \\
\text { Motiva } \\
\text { ções } \\
\text { Pessoais }\end{array}$ & $\begin{array}{l}\text { Fator 2 } \\
\text { Inovação e } \\
\text { Incentivo à } \\
\text { criação de } \\
\text { empresas }\end{array}$ & $\begin{array}{l}\text { Fator } 3 \\
\text { Caracte- } \\
\text { rísticas da } \\
\text { localida- } \\
\text { de }\end{array}$ & $\begin{array}{l}\text { Fator } 4 \\
\text { Expansão } \\
\text { económica } \\
\text { da região }\end{array}$ & $\begin{array}{c}\text { Fator } 5 \\
\text { Condições do } \\
\text { Meio } \\
\text { Envolvente }\end{array}$ \\
\hline $\begin{array}{l}\text { Desejo do fundador viver nesta localidade } \\
\text { Desejo dos colaboradores viverem nesta localidade } \\
\text { Proximidade da residência do fundador } \\
\text { O fundador nasceu nesta localidade }\end{array}$ & $\begin{array}{l}0,861 \\
0,731 \\
0,852 \\
0,811 \\
\end{array}$ & & & & \\
\hline $\begin{array}{l}\text { Incubadora de empresas na região } \\
\text { Acesso ao conhecimento gerado pelas } \\
\text { universidades, parques tecnológicos ou centros de } \\
\text { investigação } \\
\text { Incentivos de I\&D, criação de empresas ou criação } \\
\text { de emprego para localizar os negócios nesta zona } \\
\text { Feiras tecnológicas periodicamente na zona } \\
\text { Modelos de "referência" na zona }\end{array}$ & & $\begin{array}{l}0,787 \\
0,732 \\
\\
0,774 \\
\\
0,685 \\
0,635\end{array}$ & & & \\
\hline $\begin{array}{l}\text { Atitude da comunidade em relação aos negócios } \\
\text { Distância à capital do município; } \\
\text { Outras infra-estruturas físicas }\end{array}$ & & & $\begin{array}{l}0,523 \\
0,784 \\
0,650\end{array}$ & & \\
\hline $\begin{array}{l}\text { Intra-estruturas rodoviárias } \\
\text { Custo dos terrenos } \\
\text { Nível da atividade económica da região }\end{array}$ & & & & $\begin{array}{l}0,722 \\
0,639 \\
0,669\end{array}$ & \\
\hline $\begin{array}{l}\text { Acesso a boas condições de alojamento } \\
\text { Oportunidades recreativas e de lazer } \\
\text { Clima desta zona } \\
\text { Especialização das empresas da região }\end{array}$ & & & & & $\begin{array}{l}0,568 \\
0,482 \\
0,648 \\
0,473\end{array}$ \\
\hline Variância Explicada (\%) & 22,45 & 16,77 & 8,57 & 7,13 & 6,77 \\
\hline Consistência $\alpha$ Cronbach & 0,859 & 0,768 & 0,575 & 0,582 & 0,386 \\
\hline
\end{tabular}

Quadro 3 - Fatores de decisão de localização das empresas de base tecnológica: análise fatorial dos componentes principais, após rotação varimax

Fonte: Elaborado pelos autores.

$* \mathrm{KMO}=0,759$ e teste de esfericidade de Bartlett = 1347,702 (significância: 0,000) 
A análise de consistência interna de cada fator revelou valores aceitáveis de alpha para todos os fatores com a exceção do fator 5 que apresentou um valor de alpha inferior a 0,5.

Assim, analisando o agrupamento das variáveis em fatores, obtém-se a seguinte interpretação para os fatores encontrados: o fator 1 está relacionado com motivações pessoais do fundador da empresa (opção de residência dos trabalhadores e dos fundadores, residência próxima do local de localização da empresa e naturalidade). O fator 2 está relacionado com o grau de inovação (incubadora de empresas, proximidade das universidades, feiras tecnológicas), empresários de referência na região e incentivo à criação de empresas. O terceiro fator refere-se a características da localidade (atitude da comunidade face aos novos empresários, e o nível das infra-estruturas). O quarto fator refere-se à possibilidade de expansão económica que a região pode proporcionar (infraestruturas rodoviárias, custo dos terrenos e nível de atividade económica). O quinto fator refere-se a condições de meio envolvente (boas condições de alojamento, oportunidades de lazer, clima, especialização das empresas da região). Após a realização da análise fatorial, verificamos que a agregação dos fatores é diferente da que propusemos no nosso modelo conceptual (Figura 1). Assim para o caso da Beira Interior, os fatores que influenciam a localização das empresas agregam-se do seguinte modo: 


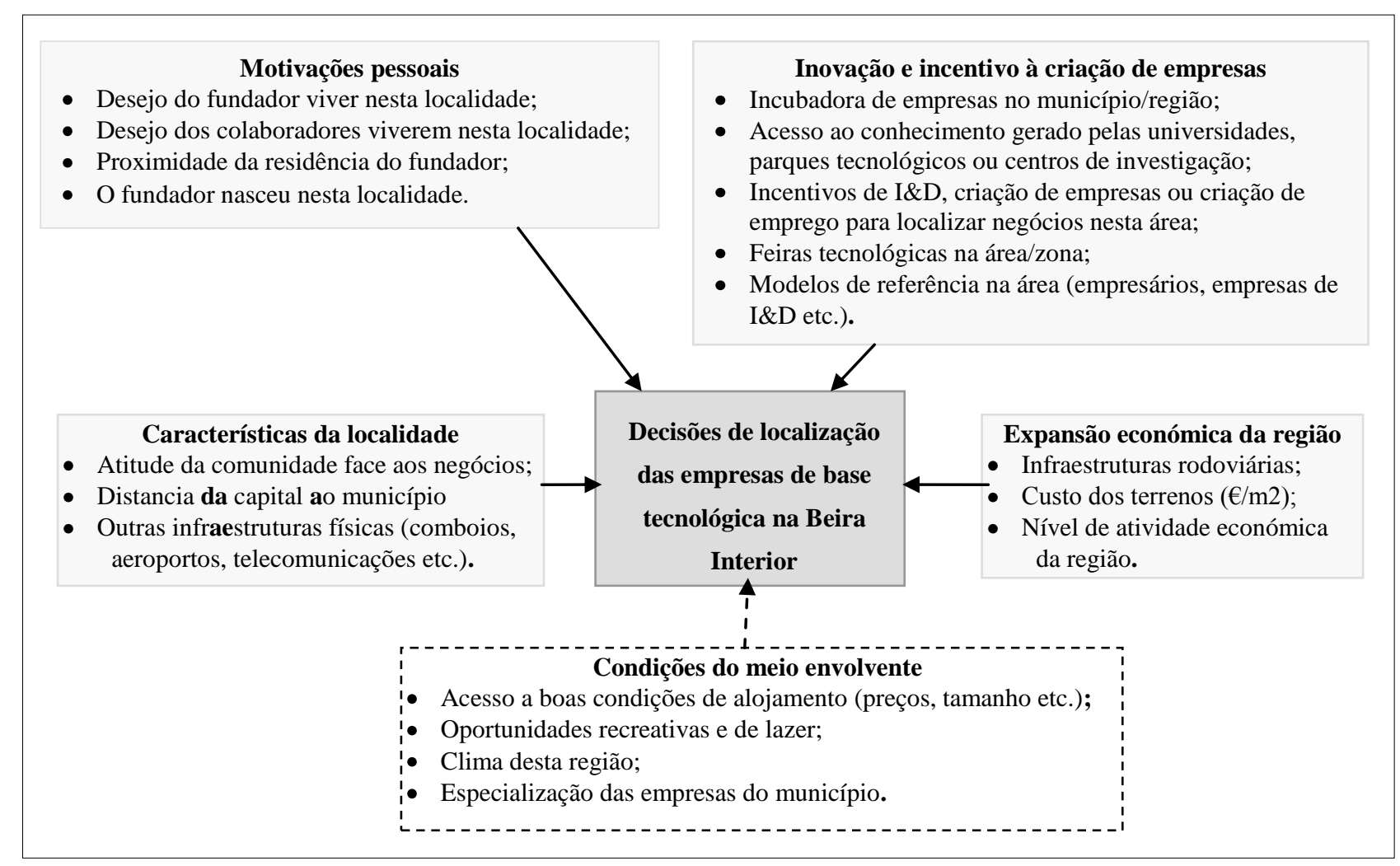

Figura 2 - Modelo Empírico.

Fonte: Elaborado pelos autores.

\section{ANÁliSE E DISCUSSÃO DOS RESULTADOS: FATORES DE LOCALIZAÇÃO DAS EMPRESAS DE BASE TECNOLÓGICA}

No sentido de aprofundar o conhecimento acerca das diferenças relativamente ao grau de concordância face aos fatores de localização em estudo, recorreu-se novamente ao teste KruskalWallis, que surge não como alternativa ao teste paramétrico, mas como o teste adequado a esta escala de medida (1- nenhuma importância, 5- muito importante), ou seja, a uma escala ordinal.

As estatísticas de teste permitem concluir que os factores "Desejo dos colaboradores em viverem nesta localidade" e "Clima desta zona" conduziram a um grau de concordância diferente nos três tipos de tecnologia, para o nível de significância de 5\%. Para 10\% verificou-se que os factores "Desejo do fundador viver nesta localidade", "Proximidade da residência do fundador", "O fundador nasceu nesta localidade", "Oportunidades recreativas e de lazer", "Distância da capital ao município" e "Nível da atividade económica do município/região" apresentam diferenças nos três tipos de tecnologia (Quadro 4). 
Para os restantes fatores não houve diferenças estatisticamente significativas. No sentido de identificar quais os fatores decisivos à localização das empresas na região da Beira Interior, segundo a classificação tecnológica (baixa, media e alta), foram criadas três variáveis denominadas por neo, inst e comp que pretendem quantificar a importância atribuída aos fatores de localização definidos como neoclássica, institucional e comportamental. No modelo de investigação podemos ver as questões associadas a cada uma destas novas variáveis.

Dada a não verificação dos pressupostos relativos à normalidade da variável dependente e homogeneidade de variâncias, recorreu-se ao teste de Kruskal-Wallis para testar se existem diferenças relativas à importância dos fatores de localização das empresas ou, de outro modo, se existem diferenças no grau de concordância com fatores relativamente ao tipo de tecnologia.

\begin{tabular}{|c|c|c|c|}
\hline Fatores de Localização & Qui-quadrado & g.l. & Sig. Assimp \\
\hline E1- Desejo do fundador viver nesta localidade & 5,02 & 2 & $0,08 * *$ \\
\hline E2- Desejo dos colaboradores viverem nesta localidade & 10,71 & 2 & $0,00^{*}$ \\
\hline E3- Proximidade da residência do fundador & 5,20 & 2 & $0,07 * *$ \\
\hline E4- Acesso a boas condições de alojamento & 0,26 & 2 & 0,88 \\
\hline E5- O fundador nasceu nesta localidade & 5,05 & 2 & $0,08 * *$ \\
\hline E6- Oportunidades recreativas e de lazer & 5,73 & 2 & $0,06 * *$ \\
\hline E7- Clima desta zona & 10,75 & 2 & $0,00^{*}$ \\
\hline E8- Atitude da comunidade em relação aos negócios & 1,56 & 2 & 0,46 \\
\hline E9- Distância à capital do município & 5,06 & 2 & $0,08 * *$ \\
\hline E10- Intra-estruturas rodoviárias & 0,80 & 2 & 0,67 \\
\hline E11- Outras infra-estruturas físicas & 1,85 & 2 & 0,40 \\
\hline E12- Custo dos terrenos & 3,27 & 2 & 0,20 \\
\hline E13- Nível da actividade económica da região & 5,74 & 2 & $0,06 * *$ \\
\hline E14- Especialização das empresas da região & 0,34 & 2 & 0,85 \\
\hline E15- Incubadora de empresas na região & 0,14 & 2 & 0,93 \\
\hline $\begin{array}{l}\text { E16- Acesso ao conhecimento gerado pelas universidades, parques } \\
\text { tecnológicos ou centros de investigação }\end{array}$ & 0,87 & 2 & 0,65 \\
\hline $\begin{array}{l}\text { E17- Incentivos de I\&D, criação de empresas ou criação de emprego } \\
\text { para localizar os negócios nesta zona }\end{array}$ & 1,63 & 2 & 0,44 \\
\hline E18- Feiras tecnológicas periodicamente na zona & 0,76 & 2 & 0,68 \\
\hline E19- Modelos de "referência" na zona & 1,67 & 2 & 0,43 \\
\hline
\end{tabular}

Quadro 4 - Teste de Kruskal-Wallis aplicado aos 19 Fatores de Localização.

Fonte: Elaborado pelos autores.

$$
*=\mathrm{p}<0,05 ; * *=\mathrm{p}<0,10
$$


As hipóteses sob estudo podem escrever-se formalmente do seguinte modo: $H_{0}: \theta_{1}=\theta_{2}=\theta_{3} \quad$ vs $\quad H_{1}: \exists i, j: \theta_{i} \neq \theta_{j}(i \neq j ; i, j=1,2,3)$. No Quadro 5, das estatísticas de teste, podemos observar a probabilidade de significância calculada assimptoticamente $(p=0,003)$, pelo que rejeitamos a hipótese $\mathrm{H} 0$, isto é, no que se refere à variável que quantifica a importância dos fatores comportamentais, concluímos que existe pelo menos um tipo de tecnologia com concordância diferente face aos fatores de localização.

Para as variáveis associadas ao fatores de localização Neoclássicos e Institucionais, não rejeitamos a hipótese de a sua influência ser idêntica para os diferentes tipos de tecnologia pois, $\mathrm{p}=0,450$ e $\mathrm{p}=0,872$, respectivamente.

\begin{tabular}{c|c|c|c}
\hline & Neo_Stand & Ins_Stand & Comp_Stand \\
\hline Qui-quadrado & 1,598 & 0,275 & 12,578 \\
\hline Graus de liberdade & 2 & 2 & 2 \\
\hline Significância Assimptótica & 0,450 & 0,872 & 0,002 \\
\hline
\end{tabular}

Quadro 5 - Estatística de teste de Kruskal-Wallis - Test Statistics(a, b)

Fonte: Elaborado pelos autores.

* a Kruskal-Wallis Test; b Grouping Variable: Tipo de Tecnologia

A análise do Quadro 6 permite verificar que os fatores associados às abordagens neoclássicas e institucionais estão correlacionadas ainda que essa correlação possa ser considerada fraca. Os fatores associados à abordagem comportamental não estão correlacionados com os demais.

\begin{tabular}{l|l|r|r|r}
\hline \multicolumn{2}{l|}{} & \multicolumn{1}{|c}{ Neo_Stand } & \multicolumn{1}{c}{ Ins_Stand } & Comp_Stand \\
\hline Neo_Stand & Pearson Correlation & 1 &, 334 &, 122 \\
\hline & Sig (2-tailed) & 195 &, 000 &, 092 \\
\hline & N &, 334 & 195 &, 193 \\
\hline Ins_Stand & Pearson Correlation &, 000 & 1 &, 001 \\
\hline & Sig (2-tailed) & 195 & &, 991 \\
\hline & N &, 122 & 201 & 198 \\
\hline Comp_Stand & Pearson Correlation &, 092 &, 001 & 1 \\
\hline & Sig (2-tailed) & 193 &, 991 & 198 \\
\hline & N & 198 & \\
\hline
\end{tabular}

Quadro 6 - Correlação dos factores de localização por tipo de abordagem.

Fonte: Elaborado pelos autores. 
Atendendo às análises efetuadas, apresentamos agora o Quadro 7 que resume os resultados face às hipóteses de investigação previamente formuladas.

\begin{tabular}{|c|c|c|c|}
\hline \multirow[t]{2}{*}{ Hipóteses } & \multicolumn{3}{|c|}{ Resultados por tipo de tecnologia } \\
\hline & $\begin{array}{c}\text { Alta- } \\
\text { Tecnologia }\end{array}$ & $\begin{array}{l}\text { Média- } \\
\text { Tecnologia }\end{array}$ & $\begin{array}{c}\text { Baixa- } \\
\text { Tecnologia }\end{array}$ \\
\hline \multicolumn{4}{|l|}{ Fatores Comportamentais } \\
\hline $\begin{array}{l}\text { H1a: O desejo do fundador em viver nesta localidade, } \\
\text { influencia a localização das empresas de alta média e } \\
\text { baixa tecnologia }\end{array}$ & Verifica-se & $\begin{array}{l}\text { Verifica-se } \\
\text { parcialmente }\end{array}$ & Verifica-se \\
\hline $\begin{array}{l}\text { H1b: O desejo dos colaboradores em viverem nesta } \\
\text { localidade influencia a localização das empresas de alta } \\
\text { média e baixa tecnologia }\end{array}$ & $\begin{array}{l}\text { Verifica-se } \\
\text { parcialmente }\end{array}$ & $\begin{array}{l}\text { Verifica-se } \\
\text { parcialmente }\end{array}$ & $\begin{array}{l}\text { Verifica-se } \\
\text { parcialmente }\end{array}$ \\
\hline $\begin{array}{l}\text { H1c: A proximidade da residência do fundador influet } \\
\text { localização } \\
\text { das empresas de alta média e baixa tecnologia; }\end{array}$ & Verifica-se & $\begin{array}{l}\text { Verifica-se } \\
\text { parcialmente }\end{array}$ & Verifica-se \\
\hline $\begin{array}{l}\text { H1d: O acesso a boas condições de alojamento } \\
\text { influencia a localização das empresas de alta média e } \\
\text { baixa tecnologia }\end{array}$ & Não se verifica & Não se verifica & Não se verifica \\
\hline $\begin{array}{l}\text { H1e: O local de nascimento do fundador influencia a } \\
\text { localização das empresas de alta média e baixa } \\
\text { tecnologia }\end{array}$ & $\begin{array}{l}\text { Verifica-se } \\
\text { parcialmente }\end{array}$ & $\begin{array}{l}\text { Verifica-se } \\
\text { parcialmente }\end{array}$ & $\begin{array}{l}\text { Verifica-se } \\
\text { parcialmente }\end{array}$ \\
\hline $\begin{array}{l}\text { H1f: As oportunidades recreativas e de lazer influenc } \\
\text { localização das } \\
\text { empresas de alta média e baixa tecnologia }\end{array}$ & Não se verifica & Não se verifica & Não se verifica \\
\hline $\begin{array}{l}\text { H1g: O clima da região influencia a localização destas } \\
\text { empresas }\end{array}$ & Não se verifica & Não se verifica & Não se verifica \\
\hline $\begin{array}{l}\text { H1h: A Atitude da comunidade em relação aos } \\
\text { negócios influencia a localização das empresas de alta } \\
\text { média e baixa tecnologia }\end{array}$ & Não se verifica & Não se verifica & Não se verifica \\
\hline \multicolumn{4}{|l|}{ Fatores Neoclássicos } \\
\hline $\begin{array}{l}\text { H2a: A distância à capital do município influencia a } \\
\text { localização das empresas de alta média e baixa } \\
\text { tecnologia }\end{array}$ & Não se verifica & Não se verifica & Não se verifica \\
\hline $\begin{array}{l}\text { H2b: As infraestruturas rodoviárias influenciam a } \\
\text { localização das empresas de alta média e baixa } \\
\text { tecnologia }\end{array}$ & Não se verifica & Não se verifica & Não se verifica \\
\hline $\begin{array}{l}\text { H2c: Outras infraestruturas físicas influenciam a } \\
\text { localização das empresas de alta média e baixa } \\
\text { tecnologia }\end{array}$ & Não se verifica & Não se verifica & Não se verifica \\
\hline $\begin{array}{l}\text { H2d: O Custo dos terrenos influencia a localização das } \\
\text { empresas de alta média e baixa tecnologia }\end{array}$ & Não se verifica & Não se verifica & Não se verifica \\
\hline $\begin{array}{l}\text { H2e: O nível da atividade económica do } \\
\text { município/região influencia a localização das empresas } \\
\text { de alta média e baixa tecnologia }\end{array}$ & Verifica-se & Não se verifica & Verifica-se \\
\hline $\begin{array}{l}\text { H2f: A especialização das empresas da região } \\
\text { influencia a localização das empresas de alta média e } \\
\text { baixa tecnologia }\end{array}$ & Não se verifica & Não se verifica & Não se verifica \\
\hline Fatores Institucionais & & & \\
\hline
\end{tabular}

Revista de Administração e Inovação, São Paulo, v. 7, n. 4, p.43-65, out./dez. 2010 


\begin{tabular}{|c|c|c|c|}
\hline $\begin{array}{l}\text { H3a: A existência de uma incubadora de empresas na } \\
\text { região influencia a localização das empresas de alta } \\
\text { média e baixa tecnologia }\end{array}$ & Não se verifica & Não se verifica & Não se verifica \\
\hline $\begin{array}{l}\text { H3b: O acesso ao conhecimento gerado pelas } \\
\text { universidades, parques tecnológicos ou centros de } \\
\text { investigação influencia a localização das empresas de } \\
\text { alta média e baixa tecnologia }\end{array}$ & Não se & Não se verifica & Não se verifica \\
\hline $\begin{array}{l}\text { H3c: Os incentivos de I\&D, de criação de empresas ou } \\
\text { de criação de emprego para localizar os negócios nesta } \\
\text { região influenciam a localização das empresas alta } \\
\text { média e baixa tecnologia }\end{array}$ & verifica & Não se verifica & Não se verifica \\
\hline $\begin{array}{l}\text { H3d: As Feiras tecnológicas realizadas periodicamente } \\
\text { na região influenciam a localização das empresas alta } \\
\text { média e baixa tecnologia }\end{array}$ & Não se verifica & Não se verifica & Não se verifica \\
\hline
\end{tabular}

Quadro 7 - Síntese dos resultados das hipóteses de investigação.

Fonte: Elaborado pelos autores.

\section{CONSIDERAÇÕES FINAIS}

Na presente investigação centramo-nos nas diversas contribuições do desenvolvimento regional e abordamos as principais teorias de localização das empresas, focando-nos fundamentalmente, em três abordagens teóricas de localização: neoclássica, comportamental e institucional. Foi precisamente a partir deste ponto que formulámos a nossa questão de investigação inicial: quais as razões que levam as empresas de base tecnológica a estabelecerem-se em determinada região? Em particular, quais os fatores de localização das empresas de base tecnológica da Beira Interior?

Com base nos resultados obtidos das análises estatísticas efetuadas identificamos, como fatores que influenciam a localização das empresas de base tecnológica da Região da Beira Interior, os seguintes: (i) o desejo do fundador em viver nesta localidade; (ii) o desejo dos colaboradores em viverem nesta localidade; (iii) a proximidade da residência do fundador; (iv) o local de nascimento do fundador; (v) o nível da atividade económica da região (este fator apenas influencia as empresas de alta e baixa-tecnologia).

De acordo com o nosso modelo conceptual, verificamos que os primeiros quatro factores pertencem à abordagem comportamental, ou seja, são fatores de ordem pessoal, e apenas o quinto e último, pertence à abordagem neoclássica. Os fatores de caráter institucional não refletiram influenciar tais decisões.

Na sequência desta questão de investigação traçamos três objetivos específicos: (i) validar empiricamente o modelo conceptual proposto, das decisões de localização das empresas de base 
tecnológica na Beira Interior; (ii) identificar quais os fatores que influenciam a localização das empresas de base tecnológica na Beira Interior; e (iii) caracterizar as empresas nos diferentes níveis de tecnologia e detectar possíveis diferenças entre esses níveis.

De acordo com o estudo empírico, foi possível verificar que as empresas de alta-tecnologia localizam-se em meios menos rurais que as de média e baixa-tecnologia. No que se refere à caracterização das empresas de alta, média e baixa-tecnologia, é de salientar que os fatores são os mesmos para os três tipos de tecnologia isto porque os empresários, quanto às suas características sócio-demograficas não têm um padrão definido para cada tipo de empresa, nem ao nível da idade, nem ao nível das habilitações, fazendo com que a importância dada aos fatores seja a mesma.

Foi, ainda, possível validar empiricamente o modelo conceptual desenvolvido, embora tenha sofrido alterações no que toca aos fatores de localização das empresas desta região de análise. Este fato sugere que sejam feitas futuras investigações, aplicadas a diferentes regiões, no sentido de averiguar os fatores que mais pesam na decisão de localização.

\section{REFERÊNCIAS}

Alberto, D. (2008). Modelos de Desenvolvimento Regional. Leitão, J., Ferreira, J., \& Azevedo, S. (Eds.). Dimensões Competitivas de Portugal - Contributos dos Territórios, Sectores, Empresas e Logística, V. N. Famalicão: Centro Atlântico.

Alonso, L. F. (1999). Modelos de crecimiento y cambios espaciales recientes en las ciudades españolas: un programa desde el fin de siglo. Papels de Economia Española, 80, 231-247.

Arauzo, J. M., \& Viladecans, E. (2006). Industrial location at the Intra-Metropolitan Level: A negative binomial approach. Estudos de Economia Espanhola, 224, FEDEA.

Audretsch, D. B., Lehmann, E., \& Warning, S. (2005). University spillovers and new firm location. Research Policy, 34, 1113-1122.

Autant-Bernard, C., Mangematin, V., \& Massard, N. (2006). Creation of Biotech SMEs in France. Small Business Economics, 26, 173-187.

Birley, S. (1985). The role of networks of cities and growth in regional urban. Journal of Business Venturing, 1, 107-117.

Capello, R. (2007). Regional Economics. Advantage texts in economics and finance, New York: Routledge.

Revista de Administração e Inovação, São Paulo, v. 7, n. 4, p.43-65, out./dez. 2010 
Christaller, W. (1933). Die Zentralen Orte in Süddeuschland. Fisher, G. Tradução para ingles de

Cooke, P. (2002). Knowledge Economies - Clusters, learning and cooperative advantage. Studies in International Business and the World Economy, London \& New York: Routledge.

Costa, M. T., Segarra, A., \& Viladecans, E. (2004). The location of new firms and the life cycle of industries. Small Business Economics, 22, 265-281.

Elgen, J., Goottschalk, S., \& Rammer, C. (2004). Location decisions of Spin-Offs from public research institutions. Industry and Innovation, 11(3), 207-223.

European Commission (1997). Rural Developments. CAP 2000 Working Document, V/1117/97.

Felsenstein, D. (1996). High technology firms and the metropolitan locational choice in Israel; A look at the determinants. Human Geography, 78(1), 43-58.

Galbraith, C. S. (1985). High technology location and development: the case of Orange County. California Management Review, 28(1), 98-109.

Grimes, S. (2000). Rural areas in the information society: diminishing distance or increasing learning capacity? Journal of Rural Studies, 16(1), 13-21.

Hayter, R. (1997). The dynamics of industrial location: the factory, the firm and the production system. New York: Wiley.

Holl, A. (2004). Manufacturing location and impacts of road transport infrastructure: empirical evidence from Spain. Regional Science and Urban Economics, 34, 341-363.

Hoover, E. (1948). The location of economic activity. McGraw - Hill, New York.

Kirchoff, B. A., \& Phillips, B. D. (1988). The effect of firm formation and growth on job creation in the United States. Journal of Business Venturing, 11, 133-149.

Lopes, R. G. (1998). Dinâmicas de competitividade territorial:Portugal por referência. Lisboa: ISCTE.

Lösch, A. (1940). Die räumliche Ordung der Witschoft. Tradução para The economics of location, Yale UP, 1954.

Maroco, J. (2003). Análise estatística com utilização do SPSS. (2a ed.). Edições Lisboa: Silabo.

Marshall, A. (1890). Principles of Economics. MaCmillan, Londres.

Meyer, M. (2003). Academic entrepreneurs or entrepreneurial academics? Research-Based ventures and public support mechanisms. $R \& D$ Management, 33, 107-115.

NCOE (2001). Embracing Innovation: entrepreneurship and American Economic Growth. National Commission on Entrepreneurship. White Paper, 1-11.

OCDE (2003). Classification of manufacturing industries based on technology. Paris: OCDE. 
Ouwersloot, H., \& Rietveld, P. (2000). The geography of R\&D: tobit analysis and a Bayesian approach to mapping R\&D activities in the Netherlands. Environment and Planning, 32, 16731688.

Raposo, M., Serrasqueiro, Z., Silva, M., Ferreira, J., Leitão, J., \& Pereira, D. (2004). Cooperação Universidade Meio Envolvente. Comissão de Coordenação e Desenvolvimento Regional do Centro - CCDRC e Departamento de Gestão e Economia.

Rego, M. C. (2003). Análise de alguns impactos regionais da Universidade de Évora no meio envolvente. Nova Economia e Desenvolvimento Regional, 2, 1019-1027.

Roper, S., \& Love, J. H. (2006). Innovation and regional absorptive capacity: the labour market dimension. Annals of Regional Science, 40(2), 437-447.

Santos, D. (2002). Teorias de Inovação de Base Territorial. Compendio de Economia Regional, APDR. Santos, D. (2005). A perspectiva territorialista. Compêndio de Economia regional, 218-228 APDR.

Silva, J. (2005). Acessibilidade, competitividade e desenvolvimento económico e social do Concelho da Covilhã. Série de Estudos Económicos, Universidade da Beira Interior.

Storey, D. J. (1994). Employment. Storey, D. J. (Ed.). Understanding the Small Business Sector, London: Routledge, Cap 6, pp. 160-203.

Trullén, J. (2001). Léconomia de Barcelona: cap a un nou model de desenvolupament. Revista Situación Catalunya, 2, 26-38.

Von Thünen, J. (1826). Der isolierte Staat in bezeihungauf landwirtschaft und national ekonomie.Traduzido de C. M. Wartenberg (1966) Von Thünen's isolated state. Pergamon Press, Oxford.

Weber, A. (1909). Über den Standort der Industrie. Traduzido por C. J. Friedrich (1928). Theory of the location of industry. University of Chicago Press, Chicago.

\section{LOCATION THEORIES APPLIED TO TECHNOLOGY-BASED FIRMS: AN EMPIRICAL}

\section{STUDY}

\section{ABSTRACT}

The study of regional development has been receiving special attention from researchers. Entrepreneurship, clusters, innovation, universities and KIBS (Knowledge Intensive Business Services) are areas of knowledge having demonstrated a leading role in contributing to regional development and, specifically, in the study of location theories of firms. This research aims to identify 
which factors influence the location of technology-based firms. In order to achieve this objective, an empirical study was developed based on a questionnaire completed by 203 technology-based firms located in the region of Beira Interior (Portugal). Results indicated the possibility of identifying key factors influencing the location of these firms. These factors are of behavioral, institutional and neoclassical nature.

Keywords: Location Theories; Technology-based firms; Regional development.

Data do recebimento do artigo: 01/09/2010

Data do aceite de publicação: 09/11/2010 